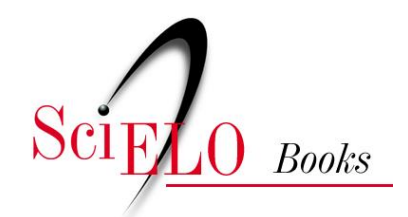

\title{
Primórdios do mito Faústico \\ o Faustbuch e o Fausto de Christopher Marlowe
}

Antonio Augusto Nery

NERY, AA. Primórdios do mito Faústico: o Faustbuch e o Fausto de Christopher Marlowe. In MAGALHÃES, ACM., et al., orgs. O demoníaco na literatura [online]. Campina Grande: EDUEPB, 2012. pp. 47-61. ISBN 978-85-7879-188-9. Available from SciELO Books <http://books.scielo.org>.

\section{(1) (1) (2)}

All the contents of this work, except where otherwise noted, is licensed under a Creative Commons Attribution-Non Commercial-ShareAlike 3.0 Unported.

Todo o conteúdo deste trabalho, exceto quando houver ressalva, é publicado sob a licença Creative Commons Atribuição Uso Não Comercial - Partilha nos Mesmos Termos 3.0 Não adaptada.

Todo el contenido de esta obra, excepto donde se indique lo contrario, está bajo licencia de la licencia Creative Commons Reconocimento-NoComercial-CompartirIgual 3.0 Unported. 


\title{
Primórdios do mito Faústico: o Faustbuch e o Fausto de Christopher Marlowe
}

\author{
Antonio Augusto Nery (UFPR) ${ }^{1}$
}

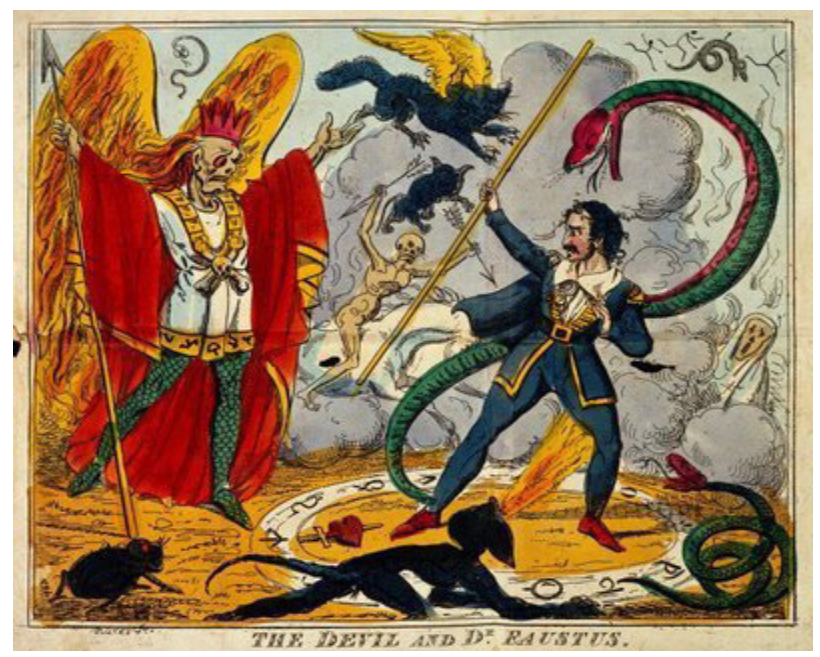

Muitas são as especulações sobre a real existência de um médico alemão que viveu no início do século XVI e que teria feito um pacto com o diabo para conseguir sabedoria plena. De acordo com Ian Watt (1997, p. 19) não se pode precisar se de fato Jorge Fausto realmente existiu, mas o crítico postula que o provável Johann Georg Faust nasceu em Knittlingen em 1480 e morreu em Staufen em 1540. Sua fama foi construída ainda em vida graças a arte da magia que teria exercido na Alemanha durante o século XVI.

1 Doutor em Letras (Literatura Portuguesa) pela Universidade de São Paulo (USP). Professor Adjunto de Literatura Portuguesa da Universidade Federal do Paraná (UFPR). E-mail: gutonery@hotmail.com. 
Obviamente que o suposto mago não era bem quisto pelas autoridades civis e religiosas, uma vez que a magia era considerada prática abominável pelo Cristianismo, contrariando principalmente a Igreja Católica que reivindicava para si a exclusividade do controle sobre o mundo sobrenatural.

Entretanto, como bem explica Ian Watt, não foi a ortodoxia católica que encampou a luta contra Fausto e sim os novos pastores protestantes, talvez pelo contexto geográfico no qual a personagem teria vivido, berço do protestantismo.

De fato, logo após o advento das teses de Lutero foi fértil a produção de uma literatura voltada a fundamentar a doutrina nascente. Entre os temas tratados por esses escritos, estava a figura do diabo:
A extraordinária floração, na Alemanha, de uma literatura especializada em 'livros do diabo', no decorrer da segunda metade do século XVI, dava testemunho da importância da figura diabólica, igualmente muito presente nos poemas e peças de teatro. A propaganda partidária dele fez igualmente grande uso para melhor diabolizar o inimigo reli- gioso, particularmente o papa, considerado como o Anticristo, anunciador do reino de Satã neste mundo. (MUCHEMBLED, 2001, p. 73).

WATT (1997) e MUCHEMBLED (2001) em suas reflexões citam vários trechos das obras de Lutero, principalmente do livro Conversações à mesa (1531-1546), nos quais o fundador do protestantismo refere-se a um certo feiticeiro Fausto que compactuava com o demônio, fato que nos faz pensar que a lenda de Fausto pode ter sido valorizada pela importância que Martinho Lutero deu à história deste seu contemporâneo. Aliás, para Watt, foram Lutero e seus seguidores os responsáveis por instituir a relação entre Fausto e o demônio, além de outras características do mito fáustico, relacionadas ao pacto com o diabo, que permaneceram para a posteridade. A história de Fausto era uma das obras que figuravam na literatura especializada do luteranismo empenhada em "explicar" o demônio² ${ }^{2}$ (Cf. WATT, 1997, p. 31).

2 Essa literatura foi muito difundida entre os anos de 1545 até 1604 e ficou conhecida 
Essas menções foram capitais para outros autores protestantes conservarem a história em suas obras de orientação e doutrina, acrescentando a ela detalhes e tendo-a como exemplificação daqueles que "se vendiam" ou faziam pactos com o diabo. Dessa forma, acabaram por instituir Fausto como exemplo do homem que pactuou com o demônio e sofreu as consequências por isso, pois, a possível morte do protagonista, operada pelo diabo, era consenso praticamente em todos os escritos desses autores (Cf. WATT, 1997, p. 30-31).

A instituição religiosa protestante não somente ajudou na difusão como também complementou a lenda que viria a ser conhecida na posteridade. De acordo com Watt, após a morte do "real" Fausto houve o aumento do interesse por sua história, justamente pelos escritores protestantes que a difundiam: "Foi essa reação negativa dos luteranos que acabou por transformar o Jorge Fausto histórico em uma figura lendária, mitológica, ao inventar seu pacto com o Demônio e seu terrível desenlace” (WATT, 1997, p. 31).

Parece-nos, portanto, que a história de Fausto passou a ser um exempla religioso, principalmente porque na Alemanha da segunda metade do século XVI, houve um empenho por parte dos protestantes em realizar uma nova prática de caça às bruxas depurada da tradição católica (Cf. NOGUEIRA, 1986, p. 73-78). Retiraram-se muitos ritos - inclusive a possibilidade dos sacramentos, o que ocasionou mais desespero por parte dos crentes, pois não se tinha nenhuma "ajuda" material para lutar contra as "forças demoníacas" -, porém a perseguição continuou vigorosa e extrema, diferenciando-se na forma, mas conservando o essencial do ritual católico: a caça aos "emissários" do diabo.

A lenda de Fausto que chegou ao conhecimento de Christopher Marlowe (1564-1593), de Goethe (1749-1832), e de vários outros autores que ajudaram a eternizar o mito fáustico, foi, provavelmente,

como Teusfelsbücher, literalmente "livros do diabo". De acordo com MUCHEMBLED (2001, p. 149): “Os Teusfelsbücher tinham sido, praticamente todos, redigidos por pastores luteranos, autores de 32 dos 39 títulos, a fim de denunciar os vícios e os pecados de seu tempo e de advertir os homens contra a prática de superstições, da magia ou da feitiçaria. Eles assumiram gêneros bem diversos: sermões, panfletos, compêndios, peças teatrais, cartas abertas, poemas didáticos, narrativas curtas... Seu valor literário era igualmente muito variável, quase sempre medíocre". 
proveniente do primeiro livro escrito sobre a vida do mago, publicado em Frankfurt no ano de 1587 por Johann Spiess. Esse livreiro e escritor de Frankfurt, que pretendeu escrever uma história verídica sobre um seu contemporâneo, é considerado aquele que permitiu a Mefistófeles tornar-se figura recorrente ao longo de cinco séculos da literatura ocidental (Cf. WATT, 1997, p. 34).

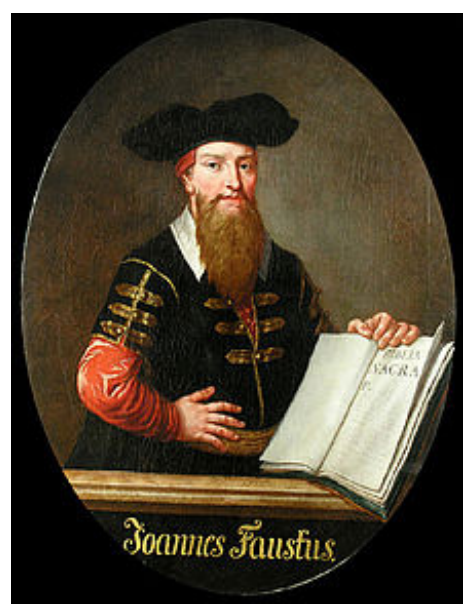

A obra era um volume de 227 páginas, intitulada Historia von dr. Johann Fausten, mas que ficou conhecida apenas como Faustbuch. Nela, a influência luterana que mencionamos acima já estava posta, mas a ideia de pacto, com detalhes sobre um contrato realizado para a morte do protagonista, só seria veiculada a partir dessa publicação ${ }^{3}$.

O texto pauta-se justamente na ideia do acordo e das desgraças que Fausto vivera por ter pactuado com o demônio, bem como nas extensas elucubrações entre Fausto e Mefistófeles que perpassam assuntos relativos à magia, teologia, astronomia e as viagens empreendidas

3 Segundo MUCHEMBLED (2001, p. 83) a ideia de pacto com o demônio constituia-se aos olhos da Instituição religiosa uma falta muito grave e repreensível, justamente pelo fato de que tal ato significava que o indivíduo estava por livre e espontânea vontade entregando-se a Satanás, diferente de outros que podiam ser ludibriados. Para o crítico essa ideia começou a ser difundida e severamente punida no contexto da Inquisição quando as feiticeiras eram acusadas de se doarem espontaneamente para o diabo. Na trama faustiana podemos conceber o pacto como um avanço, haja vista tornar-se mais um dos elementos da história que representa a liberdade de escolha individual do protagonista, sem ser cerceado por qualquer força coercitiva. 
pelo protagonista. Esses temas também estarão presentes nos diálogos das outras futuras revisitações do mito fáustico, mas as semelhanças parecem parar por aí, pois o interesse da narração do Faustbuch reside na moral retirada das cenas protagonizadas por Fausto e por Mefistófeles, em uma clara intenção proselitista, estando as duas personagens desfocadas na narração, bem ao contrário daquilo que irá acontecer já nas primeiras releituras da história, como a peça de Christopher Marlowe que logo mais analisaremos.

No Faustbuch está presente, principalmente na parte final, a preocupação do protagonista com a danação e o fim trágico que o aguarda demonstrando a angústia e a necessidade do arrependimento dos supostos erros cometidos perante Deus. Embora não se tenha detalhes da morte, fica claro que Mefistófeles cobra o acordo firmado e retém para si a alma do intrépido mágico.

A moral reiterada no desfecho é de que o futuro daqueles que desafiam Deus, os orgulhosos, os soberbos e os que possuem ambição desmedida, é o convívio eterno com Satanás e com o inferno.

A instituição religiosa, especialmente Lutero e sua Igreja nascente, aproveitou-se muito desse desfecho do Faustbuch para aplicar sua moral e exemplificar para os fiéis o imutável fim de quem se aliava com o demônio, conforme explica Ian Watt:

(...) a danação de Jorge Fausto foi dada a conhecer postumamente mediante a impressão de numerosos panfletos e livros populares; (...) o ímpeto daquela danação veio através da obsessão de Lutero em conceber a vida como um perpétuo duelo contra Satanás. Lutero indicava o Diabo para explicar cada tentação, dúvida ou episódio desagradável em sua vida pessoal. (WATT, 1997, p. 27, negrito nosso).

Se comparado à lenda, há uma grande mudança entre aquilo que era veiculado na oralidade e o que foi escrito no Faustbuch sobre a vida do Doutor Fausto. O pensamento luterano transparece ter sido, de fato, fundamental para o desenvolvimento desta primeira ficção que teve Fausto como protagonista. 
O demônio permanece aqui com a essência medieval, de perdedor das almas, servindo aos propósitos moralizantes cristãos. Seus discursos na trama são longos e substanciais, mas, na verdade, servem apenas para revelar os detalhes do acordo firmado com o sangue de Fausto, o que decretou a perdição da alma do mágico e o tornou um homem sem futuro.

A história de que após conceder benefícios, o diabo exigia em contrapartida a alma do indivíduo, já estava presente nos manuais de caça às bruxas. Esses livros traziam inclusive muitas indicações de como o processo se dava, entre elas estava o famigerado acordo firmado com o sangue da "vítima". De acordo com BRASEY (2006, p. 46):

Em troca de tais benefícios, [o diabo] mandava o novo vassalo assinar um pacto redigido em um pergaminho virgem e assinado com o próprio sangue, antes de lhe imprimir sua marca em algum lugar no corpo. Esta era facilmente reconhecível pela forma que sugeria: lebre, pata de sapo, gato preto ou cão. Indelével, só podia ser apagada pelo próprio demônio. Era justamente essa "marca do Diabo", tido por insensível, que os inquisidores se empenhavam em procurar no corpo dos supostos bruxos.

Além do mais, histórias de personagens que entregaram sua alma ao diabo, em troca de algo, eram uma constante em tempos anteriores ao período no qual viveu o suposto verdadeiro Fausto: "Desde a mais remota antiguidade e ao correr da Idade-Média não faltaram exemplos que tivessem entregado ao demo ou que lhe tivessem prometido a alma em troca de benefícios neste mundo: de poder, de riqueza, etc." (CABRAL, s.d., p. 11) ${ }^{4}$.

4 WATT (1997) ao estudar o mito fáustico, também explica que a noção de que somente a magia diabólica possibilitaria a satisfação de todos os desejos terrenos sempre esteve presente no imaginário ocidental ao longo dos séculos, quando se pensava nos poderes advindo do reino sobrenatural. Talvez tal noção foi desenvolvida a partir dos próprios Evangelhos, por intermédio das menções feitas a Satã em algumas passagens dos livros e das explicações que os evangelistas davam a elas. A menção mais significativa, sem dúvidas, é quando o diabo tenta Jesus no deserto. Satã propõe várias vantagens para Cristo, 
A cena do acordo feito com o sangue permanecerá na maioria das outras releituras sobre a vida de Fausto. O principal objetivo, sem dúvidas, é explicitar e corroborar os sentidos, os efeitos e a ligação do pacto "sanguinário" com a danação do protagonista no desfecho da trama.

Portanto, não precisamos pensar muito para entender o porquê de se ter um Mefistófeles tão eloquente, presente e companheiro do protagonista desde esta primeira versão da história de Fausto e que permanecerá com o mesmo sentido em muitas outras ficções posteriores. Watt expõe os motivos e com qual finalidade concebe-se o diabo neste período inicial de releitura do mito fáustico:

O mito do Fausto desponta no momento em que o Cristianismo, no seu desenvolvimento, pensa ter polarizado os mundos do humano e do sobrenatural em conflito entre o mal e o bem, conferindo à luta dentre as duas partes uma nova intensidade e um novo vigor. Isso inevitavelmente proporcionou ao Diabo e a sua hierarquia uma importância teológica e psicológica sem precedentes. (WATT, 1997, p. 27).

De acordo com Ian Watt: "O moralismo vulgar e complacente do autor do Faustbuch reflete os aspectos da caça ao diabo empreendida pelos luteranos na Alemanha, sem contudo passar do superficial" (WATT, 1997, p. 40). Essa superficialidade a que se refere Watt pode ser o fato de que Faustbuch não conseguiu refletir com profundidade os aspectos da "caça ao diabo e a seus emissários" realizada pelos protestantes, pois, conforme explicita o crítico, a intensidade das perseguições não diferenciava-se muito da "caça às bruxas" empreendida pelos católicos: "luteranos, calvinistas e católicos romanos foram igualmente ativos na caça às feiticeiras” (Cf. WATT, 1997, p. 29).

caso ele se abstenha dos projetos e desígnios de Deus. Entre as ofertas estão o poder sobre todo o mundo, a detenção de grande riqueza material e a supressão da fome, em suma, o ter, o poder e o ser. Jesus em nenhum momento desclassifica, contesta, ou desautoriza o poder de Satanás em conceber tais proezas, apenas ordena, de forma vaga, que o demônio evada-se: "Para trás, Satanás, pois está escrito: Adorarás o Senhor teu Deus e só a ele servirás” (Cf. MT 4, 11; LC 4,12; MC 1, 12s). 
Mesmo sendo perceptível o comprometimento do Faustbuch com as descrições do diabo medieval, bem como com o moralismo cristão protestante, tendo fins proselitistas e doutrinários, não podemos deixar de notar, todavia, que há certo avanço no desenvolvimento da personagem do diabo em comparação com outros textos que figuravam neste período em toda a Europa, como os diversos livros doutrinais e teológicos de "caça às bruxas".

Há na obra uma considerável atenção dada à personagem de Mefistófeles, ele tem direito à fala, com longos discursos e, mesmo que esses sirvam a interesses moralistas, através do diálogo com Fausto podese perceber a proximidade de Mefistófeles com os lamentos humanos, bem como a expressão de elementos individualistas que é marca registrada de Fausto, principalmente nas releituras vindouras sobre o mito.

Talvez seja esta pequena inovação difundida pelo Faustbuch que seduzirá outros escritores e os farão reler Fausto e Mefistófeles, incrementando não somente a figura do protagonista, mas, também, a do "anjo negro".

Partamos para a averiguação de uma das primeiras obras a fazer uma releitura do mito fáustico, a peça teatral The Tragical History of the Life and Death of Doctor Faustus, escrita provavelmente em 1592, pelo inglês Christopher Marlowe.

Aproveitando-se da tradução inglesa do Faustbuch ${ }^{5}$, Marlowe desenvolveu sua ficção de forma inovadora. Conforme WATT (1997, p. 42), foi ele quem estabeleceu o mito, e permitiu que permanecesse vivo na literatura e no teatro, para que, assim, dois séculos depois, Goethe desenvolvesse sua obra clássica que caracterizou, fundamentou e eternizou o mito literário que chegou a contemporaneidade.

Marlowe desenvolve sua história em plena efervescência intelectual, incentivado pela atmosfera criativa do teatro elisabetano. A ficção, com muitos contornos trágicos, expressa de forma concisa a excitação pelo conhecimento, o entusiasmo pela beleza terrena e a concepção de danação espiritual que vigorava no período renascentista.

5 Conforme CABRAL (s.d., p. 12) o Faustbuch foi traduzido para o inglês em 1592 por um anônimo que se identificou apenas com as iniciais P.F. e até nossos dias não há informações sobre sua identidade. 
Para WATT (1997, p. 44): “as maiores contribuições de Marlowe à substância do mito do Fausto podem ser resumidas em três tópicos: escolha da vocação individual; alienação acadêmica; e danação eterna". Segundo o crítico é a partir desta ficção que se tem um Fausto dedicado ao conhecimento para além do universo restrito de uma só área, com várias opções de escolhas de acordo com os desejos da vontade individual.

Nas falas iniciais do protagonista nota-se o drama vivenciado pelo pensamento individualista nascente, pois, lado a lado, estão as diversas expectativas quanto às possibilidades profissionais e as desilusões relativas aos diversos impedimentos de se exercer a profissão depois de formado, ou seja, questionamentos sobre o fato de se ter várias possibilidades de formação, sem a garantia de um futuro promissor. A saída para Fausto nesse imbróglio reside na busca pela magia:

Fausto: Só me rumina a mente em nigromancia,

Pra mim, Filosofia é escura, odiosa,

Direito e Medicina são mesquinhos,

De todas a mais baixa é Teologia,

Desagradável, rude, ignara e vil.

Só a magia, a magia me encanta! (MARLOWE, s.d., p. 32).

Muito próximo disso está o desejo de abarcar todo o conhecimento do mundo e dos mistérios sobrenaturais, fatos que contradiziam as orientações das instituições religiosas, tanto católica quanto protestante. Nos discursos do protagonista fica clara a afronta ao universo restrito proposto pelas Instituições da época e patente que tal concepção precisava ser superada. Há na história uma valorização de particularidades individuais e não morais do indivíduo, além da aventura de transpor as possibilidades propostas pelo contexto ao qual se estava inserido.

Trata-se, portanto, do início da divinização do homem e da relativização de Deus, ao menos daquele Deus descrito pelas Igrejas da época. Processo esse que será muito difundido nas produções dos escritores do século XVI, período dividido entre a religiosidade medieval e o humanismo renascentista. Parece-nos, portanto, que da obra de Marlowe ecoou para a posteridade a visão universalista do conhecimento, a exaltação do 
ego individual e a importância dada às escolhas particulares voltadas ao futuro que se apresenta para cada indivíduo. Consoante Watt:

A idéia medieval de que cabia à religião e à moral conter o indivíduo no seu lugar hierárquico, aquele que lhe foi reservado pela sociedade, era frontalmente contrária à ideologia da moderna sociedade individualista, com seu pressuposto de que cada indivíduo deveria ter igual oportunidade. (WATT, 1997, p. 48).

Por todas essas particularidades, Ian Watt (1997, p. 52) defende que o Fausto de Marlowe pode "ser visto como a imagem fundadora de um dos pressupostos básicos, ainda que irreal, do individualismo secular moderno", ao que complementa "[...] podemos concluir com boa dose de razão que a principal contribuição de Marlowe ao mito do Fausto foi ter dado uma nova dimensão e uma nova intensidade aos conflitos básicos do individualismo emergente" (WATT, 1997, p. 56).

Marlowe estava limitado, obviamente, pelo contexto no qual escreveu, não podendo aprofundar sua causa: "Marlowe alinhou-se no Doctor Faustus com a ortodoxia religiosa" (WATT, 1997, p. 38). Percebemos isso sobremaneira no final da obra quando se nota, nos dizeres de Fausto, certo arrependimento e remorso por ter pactuado com Satanás e obtido todos os favores que solicitou:

Fausto: Ó Deus,

Se não quiser's salvar a minha alma,

Por Cristo, cujo sangue me remiu,

Põe algum fim ao meu penar eterno!

Mil anos no Inferno viva Fausto,

Cem mil, mas...finalmente... seja salvo!

Oh! P’rás almas condenadas não há têrmo!

Fausto morreu. Que o seu caso infernal, E desgraça, ó pudentes, vos exortem

A ficar pela mera admiração

Perante o proibido, cujo abismo

Aos audazes como êle, incita a mente

A fazer mais, que o jus do Céu consente (MARLOWE, s.d., p. 129-130). 
A morte, preço pago pelo Fausto de Marlowe por querer desenvolver seus anseios individuais, será uma constante que poderíamos atribuir ao pensamento cristão advindo desde a primeira ilustração oficial da vida do mágico no Faustbuch. É a mensagem clara dada pelas instituições religiosas do que poderia ocorrer com aqueles que tentassem sair do coletivismo e da autoridade dos poderosos. A lição moral está nítida nesses trechos finais do drama. A semelhança da obra do escritor inglês com o Faustbuch, relacionadas às pretensões moralizantes e de exemplo para os cristãos, são evidentes.

Todavia, em muitos outros aspectos, há evoluções na retomada da história de Fausto feita por Marlowe, e a figuração de Mefistófeles é uma delas.

Watt propõe que o processo do pensamento individualista iniciou-se no Renascimento: "[..] em decorrência do Renascimento e da Reforma, a primazia do indivíduo sobre o coletivo tornou-se característica definidora da moderna sociedade ocidental em seu conjunto" (WATT, 1997, p. 236). A apologia era feita à livre escolha, à valorização da vida privada, ao auto -aperfeiçoamento, seja de ordem intelectual ou física. Era a possibilidade de se dizer aquilo que se pensava, mesmo que o discurso possuísse caráter obsceno, de galhofa ou de crítica social ferina. Embora essas características já estivessem presentes na literatura medieval - pensemos nas cantigas de escárnio e maldizer, por exemplo - foi, de fato, no Renascimento que a crítica apontou para questões relacionadas ao individualismo.

Parece-nos que Mefistófeles no Doctor Faustus assume uma nova faceta a partir dessas mudanças que se desenvolviam. Embora limitado pelo contexto histórico e o imaginário relativo ao demônio que ainda vigorava, Marlowe apresenta diferenças consideráveis na composição da figura demoníaca, diferenciando-se das representações medievais, principalmente dos manuais de caça às bruxas. Em parte, esse "novo" diabo, impulsionado pelo "novo homem" que surgia, é redesenhado pelo protagonista, Fausto. Na primeira cena na qual Mefistófeles aparece, Fausto exige que ele se apresente com outro aspecto, ironicamente, como um "velho franciscano piedoso", alguém provavelmente apreciável na época do ponto de vista religioso:

Fausto: Ordeno-te que vás mudar de forma, Que horrendo estás demais p'ra me servir.

Volta tal qual um velho franciscano:

Convém piedoso aspecto a um diabo...

(MARLOWE, s.d., p. 40). 
Nota-se certa intimidade de Fausto com o demônio nos longos diálogos entre os dois. Além dessa inovação para o contexto histórico, da proximidade de um humano com um representante das Trevas, todas as exigências de Fausto feitas à Mefistófeles podem ser tidas como heresias graves, pois demonstram incompatibilidades com os preceitos da Instituição religiosa.

Mefistófeles está em cena para ser exclusivamente o intermediário entre os desejos de Fausto e a concretização efetiva deles, constituindose peça fundamental no desempenho do protagonista. O fato da obra ser difundida em um período no qual apologias eram feitas a um pensamento individualista nascente, possivelmente fez com que a permanência da crítica impingida pela Instituição religiosa à história de Fausto - a de que por desejar o conhecimento ilimitado ele havia pactuado com o demônio -, se transformasse na perspectiva de que Satanás era "amigo íntimo" de todos os homens que manifestavam o desejo de desenvolver seu intelecto e o livre pensamento.

Satanás já começa a transparecer aqui também certa humanidade que seria apreciada e desenvolvida pelos escritores que revisitariam a história de Fausto futuramente. Observemos um dos trechos de seus discursos no qual temos a expressão de uma fraqueza humana, a angústia, por ele ser um anjo decaído que perdeu o céu e a oportunidade de desfrutar do Supremo Bem:

Mefist: Isto é o inferno, e fóra dêle não estou!

Pois pensas que eu, que vi de Deus a face,

E os eternos prazer's do Céu provei,

Não me atormento com dez mil infernos,

Por'star provado do perene bem?

Oh, deixa, Fausto, essas perguntas frívolas,

Que terror causam à minha alma ansiosa...

Fausto: Quê? Tão sentido o grande Mefistófeles,

Por dos prazer's do Céu privado estar? (MARLOWE, s.d., p. 44).

Embora as falas de Mefistófeles tenham tonalidades proselitistas angústia e tormenta por estar privado das benesses do Supremo Bem - suas palavras presentes no texto do dramaturgo inglês também fazem 
menção às dúvidas acerca da danação eterna. Tanto os reformistas quanto os católicos haviam consolidado a doutrina da danação para os maus e do paraíso celeste para os bons; de um lado os anjos e a virtude e de outro o demônio e o vício, isso tudo como um poderoso sistema de coerção para efetivarem a moral, a ordem social e a crença.

$\mathrm{Na}$ obra de Marlowe, temos um Fausto envolto nesse dilema. Mesmo que levemos em conta trechos como o citado acima, no qual percebemos Mefistófeles ressentindo-se da queda do Paraíso e envolto pela sensação de perda, ao contrário de Fausto que o ridiculariza, temos, em alguns episódios iniciais, Fausto imerso em questionamentos voltados a si mesmo, se segue em frente ou não com o pacto diabólico:

Fausto: Fausto, hás-de agora

Ser condenado, e salvo se não podes.

No céu e em Deus, p'ra que pensar então?

Fóra com tais loucuras, desespera,

Desespera de Deus, crê no diabo,

Sê resoluto, Fausto, não recues.

Porque vacilas? Diz-me algo ao ouvido:

- Deixa a magia, volta para Deus!

Ai, para Deus bem quer' Fausto voltar...

P'ra Deus? - Ele não te ama....

É teu próprio apetite que serves,

E dêl'te vem o amor por Belzebú...

Um altar e uma igreja lhe hei-de erguer,

Doar-lhe o sangue de recém-nascidos! (MARLOWE, s.d., p. 53-54).

Entretanto, mesmo constatando angústia e ambiguidade no decorrer da história, percebemos um Fausto que se sobrepõe às indecisões e questionamentos maniqueístas, representando os homens insatisfeitos que preferiram aquilo considerado "execrável" pelas autoridades a ser submetido a elas. No trecho acima temos na frase "Ai, para Deus bem quer' Fausto voltar.../ P'ra Deus? - Ele não te ama..." o resumo deste sentimento é o ponto novo que a peça de Marlowe inaugura na trajetória das várias versões da história de Fausto, qual seja o questionamento de que Deus não ama o homem porque não o deixa ser livre enquanto indivíduo que possui suas próprias vontades e desejos. 
Assim, temos um ser humano que preferiu gozar plenamente seus instintos e desejos terrenos, e ir para o inferno, a esperar uma suposta alegria eterna no Paraíso.

Fausto: Tivesse eu tantas almas, como há estrêlas, Tôdas por Mefistófeles as daria

Por êle serei Imperador do mundo,

Uma ponte farei nos ares moventes

P'ra o oceano passar co'um bando de homens (MARLOWE, s.d., p. 46).

A grande mensagem que paira no final é que ao contrário de ser levado aos infernos como no Faustbuch, embora com certa hesitação, Fausto optou por ele. A livre escolha ficou posta e valorizada. A peça de Marlowe finda com esta mensagem. Mefistófeles permanece como aquele que ajuda o protagonista a realizar seus desejos e anseios contrários à ordem social vigente. 


\section{Bibliografia}

BÍBLIA SAGRADA - Tradução do Centro Bíblico Católico. São Paulo, Ave Maria, 1994.

BRASEY, Édouard. Como se vendia a alma ao diabo. In: Revista História Viva - Grandes Temas, ed. 12. São Paulo, Duetto Editorial, 2006, p. 41-47.

CABRAL, A. de Oliveira. Prefácio. In: MARLOWE, Christopher. O "Fausto". Trad. de A. de Oliveira Cabral. Lisboa: Papelaria Fernandes Livraria, s.d.

MARLOWE, Christopher. O "Fausto". Trad. de A. de Oliveira Cabral. Lisboa: Papelaria Fernandes Livraria, s.d.

MUCHEMBLED, Robert. Uma história do Diabo: séculos XII-XX. Rio de Janeiro, Editora Bom Texto, 2001.

NOGUEIRA, Carlos Roberto F. O diabo no imaginário cristão. São Paulo, Editora Ática, 1986.

WATT, Ian. Mitos do individualismo moderno - Fausto, Dom Quixote. Dom Juan, Robinson Crusoé. Rio de Janeiro, Jorge Zahar Editor, 1997.

\section{Imagens:}

The Devil and Dr. Faustus. Disponível em http://marloweobra.files.wordpress.com/2009/01/faustus1.jpg, 07/10/2012

Joanes Faustus. Disponível em http://upload.wikimedia.org/wikipedia/ commons/thumb/5/58/Idealportr\%C3\%A4t_Joannes_Faustus.jpg/220px-Idealportr\%C3\%A4t_Joannes_Faustus.jpg,07/10/2012 
